\title{
ÉPOCA DE SEMEAÇÃO DA GUAXIMA
}

\author{
J. C. Medina
}

Engenheiro agrônomo, Seção de Plantas Fibrosas Diversas, Instituto Agronômico de Campinas

\section{1 - INTRODUÇÃO}

A guaxima (Urena lobata L.) é uma planta subarbustiva e perene, amplamente distribuída pelas regiões tropicais e subtropicais, de cujo caule se extrai uma fibra sedosa e flexível, industrialmente equivalente à juta indiana. A sua distribuição geográfica no Brasil é bastante ampla, sendo talvez, depois das plantas do gênero Sida, a malvácea de ocorrência mais comum. Daí a vasta sinonímia pela qual é vulgarmente conhecida : guaxima, carrapicho, guazuma, malva roxa, guaxima roxa, uacima, malvaísco, ibaxama, caquibosa, etc., sendo que, em 1900, uma indústria passageira a designou ainda pelo nome de aramina.

Os indígenas do Brasil já empregavam as embiras de guaxima para a confecção de rêdes e cestos, e os primeiros colonizadores utilizavam as filaças na fabricação de cordas e amarrilhos. Apesar de tôda a propaganda, ressaltando as qualidades têxteis dessa fibra, e de ter sido, em várias ocasióes, $U$. lobata lembrada como planta têxtil sucedânea da juta, a sua cultura jamais conseguiu implantar-se de fato em nosso meio. Excetuando-se algumas tentativas esporádicas de implantação da cultura nos Estados de São Paulo, Rio de Janeiro e Espírito Santo, a exploração da guaxima constituiu sempre mera indústria extrativa, aproveitando as imensas reservas naturais. Mesmo assim, a sua importância sòmente se evidenciou depois de 1942, devido às dificuldades criadas pela guerra na aquisição da juta asiática, e consequente obrigatoriedade do emprêgo de fibras nativas em mistura com a fibra importada.

Fora do Brasil, a $U$. lobata é ainda explorada em Madagáscar, onde é conhecida pela denominação de "paka" ; no Congo Belga, na região de Leopoldville, e, em menor escala, na Africa Oriental Francesa, Moçambique e Angola. Em Assam, é conhecida pela denominação de "juta de Yangli".

A cultura da guaxima também já foi tentada em Cuba, onde é conhecidá pelas denominações de "malva blanca", "cadillo" e "guizazo", e, nos Estados Unidos, na Flórida, sob a designação de "caesar weed".

Esta planta ocorre ainda, em estado subespontâneo, em outras regiões tropicais da Āsia, África e América Central, e, esporàdicamente, tem sido objeto de aproveitamento como indústria extrativa pelas populações nativas.

A guaxima pode substituir perfeitamente a juta indiana nas nossas fábricas de aniagem, que normalmente já a consomem em mistura com esta, e que a consideram como seu melhor sucedâneo. Porisso, a $U$. lobata foi incluída no plano trienal de pesquisas da Secção de Plantas Fibrosas Diver- 
sas do Instituto Agronômico. Essas pesquisas tinham por finalidade determinar o seu comportamento e produção, em diferentes regiões e tipos de solo do planalto paulista, em quatro épocas de semeação, juntamente com o Hibiscus cannabinus L. (papoula de São Francisco), Crotalaria juncea L. e Corchorus olitorius L. (juta).

Em trabalho anterior ( $\left.{ }^{(}\right)$, já foram discutidos os resultados obtidos com o $H$. cannabinus, nos anos agrícolas de 1947/48, 1948/49 e 1949/50. O presente trabalho tem por objetivo apresentar os resultados obtidos com a $C$. lobata durante êsse triênio de experimentação.

\section{2 - MATERIAL E MÉTODOS}

As sementes de $U$. lobata, utilizadas na instalação dos experimentos, provêm de uma amostra fornecida, em 1941, pelo saudoso engenheiro agrônomo Ubirajara Pereira Barreto, que pertenceu à Divisão de Fomento Agrícola Federal, em São Paulo.

As parcelas semeadas com guaxima, repetidas quatro vêzes, foram subdivididas em quatro subparcelas de $10 \mathrm{~m}^{2}$ cada uma, correspondendo às seguintes épocas de semeação:

EPOCA

Primeira

Segunda

Terceira

Qusrta

\section{Data de semeaşão}

15 de outubro

30

15 de novembro

30 ,",

A semeação foi feita em linha corrida, na base de 1 grama de sementes por metro linear, sendo que nos experimentos de 1947/48 cada subparcela compreendia 12 fileiras de plantas distanciadas, entre si, 20 centímetros, e nos dois anos agrícolas seguintes, apenas 10 fileiras de plantas, com distância, entre si, de 30 centímetros. $\mathrm{Na}$ colheita, as duas fileiras externas foram desprezadas.

Não se aplicou, em nenhum dos anos agrícolas, qualquer adubação nos experimentos.

Os dados obtidos se referem à produção de caules enfolhados, que, em geral, foram cortados durante a fase de pleno florescimento das plantas. Os dados de "produção provável" de fibra, aqui citados, baseiam-se em resultados de um ensaio preliminar de maceração, efetuado em 1944, no qual se obtiveram, em média, para a $U$. lobata, $5,2 \%$ de fibras sêcas sôbre caules verdes enfolhados.

\section{3 - RESULTADOS}

\section{1 - ANO AGRÍCOLA 1947/48}

Neste ano agrícola foram instalados 11 experimentos, distribuídos nas localidades indicadas no quadro 1.

(1) Medina, J. C. Efeito da época de semeação na produção do Hỉbiscus cannabinus L. Bramantia 10: 125-137. fig. 1-3. 1950. 
Quabro 1.-Produsăo média de caules verdes enfolhados da U. lobata, em quilos por subparcela de $10 \mathrm{~m}^{2}$, em cada época de semenção e localidade, nos experimentos do ano agrícola 1947/48. Médias de 4 repetições

\begin{tabular}{|c|c|c|c|c|c|c|}
\hline \multirow{2}{*}{ Localidades } & \multicolumn{4}{|c|}{$\begin{array}{c}\text { Prodição média de massa verde nas } \\
\text { épocass }\end{array}$} & \multirow{2}{*}{$\begin{array}{c}\text { "F" } \\
\text { relativo } \\
a \\
\text { épocas }(1)\end{array}$} & \multirow{2}{*}{$\begin{array}{c}\text { Diferença } \\
\text { mínima } \\
\text { significativa } \\
(\mathrm{P}=0,05)\end{array}$} \\
\hline & Primeirs & Segunda & Terceira & Quarta & & \\
\hline & $\mathrm{kg}$ & $k g$ & $\mathrm{~kg}$ & $k g$ & & $\mathrm{~kg}$ \\
\hline l'indorama & 66,6 & 61,4 & 41,9 & 32,5 & $58,27^{* *}$ & $\pm 3,4$ \\
\hline Mococa & 37,1 & 30,8 & 24,8 & 16,2 & $20,12^{* *}$ & $\pm 3,7$ \\
\hline Ribeirão Prêto & 46.3 & 48,2 & 40,7 & 31,5 & $6,89^{*}$ & $\pm 4,6$ \\
\hline Capão Bonito....... & 29,4 & 28,2 & 30,8 & 23,6 & $5,91^{*}$ & $\pm 2,0$ \\
\hline Tatuí _......... & 35,4 & 32,2 & 26,0 & 24,2 & $11,99^{* *}$ & $\pm 2,4$ \\
\hline Limeira & 22,3 & 18,1 & 15,7 & 10,9 & $12,30^{* *}$ & $\pm 2,1$ \\
\hline Santa Rita .... & 49.7 & 38,6 & 19,4 & 9,4 & $245,59^{* *}$ & $\pm 1,9$ \\
\hline Jaú .......... & 27,9 & $2 !, 0$ & 14,9 & 11,4 & $42,38 * *$ & $\pm 1,8$ \\
\hline Campinas & 28,3 & 23,7 & 22,6 & 17,6 & $4,00^{*}$ & $\pm 3,5$ \\
\hline Tietê .... & 28,5 & 23,0 & 17,9 & 15,4 & $4,72^{*}$ & $\pm 4,3$ \\
\hline Tupi $\ldots \ldots$ & 34,7 & 30,1 & 18,7 & 17,7 & $12,40^{* *}$ & $\pm 3,8$ \\
\hline
\end{tabular}

$\left({ }^{1}\right)^{*}=$ significativo $(5 \%) * *=$ altamente significativo.

No experimento localizado em Ribeirão Prêto, ocorreu um rcgular "murchamento" das plantas da primeira e segunda épocas de semeação, provàvelmente pelo ataque de nematóides. Devido ao atraso no preparo da terra, a primeira época de semeação dos experimentos de Mococa e Limeira foi transferida para 20 e 30 de outubro, respectivamente, conservando-se, porém, o mesmo intervalo de 15 dias entre as demais épocas de semeação.

No quadro 1 se faz indicação dos dados médios de produção de caules verdes enfolhados, em quilos, $\mathrm{cm}$ cada época de semeação e localidade, assim como do efeito das épocas sôbre a produção e os valores da diferença mínima significativa para $\mathbf{P}=0,05$. Os dados do quadro 1 mostram que $\mathrm{cm}$ sete localidades - Pindorama, Mococa, Tatuí, Limeira, Santa Rita, Jaú e Tupi - o efcito das épocas de semeação sôbre a produção de caules verdes enfolhados foi altamente significativo, ao passo que, em quatro localidades - Capão Bonito, Campinas, Tietê e Tupi - foi apenas significativo.

Na figura 1 estão representadas as produções de caules verdes enfolhados em cada época de semeação, em toncladas por hectare, e por localidade. 


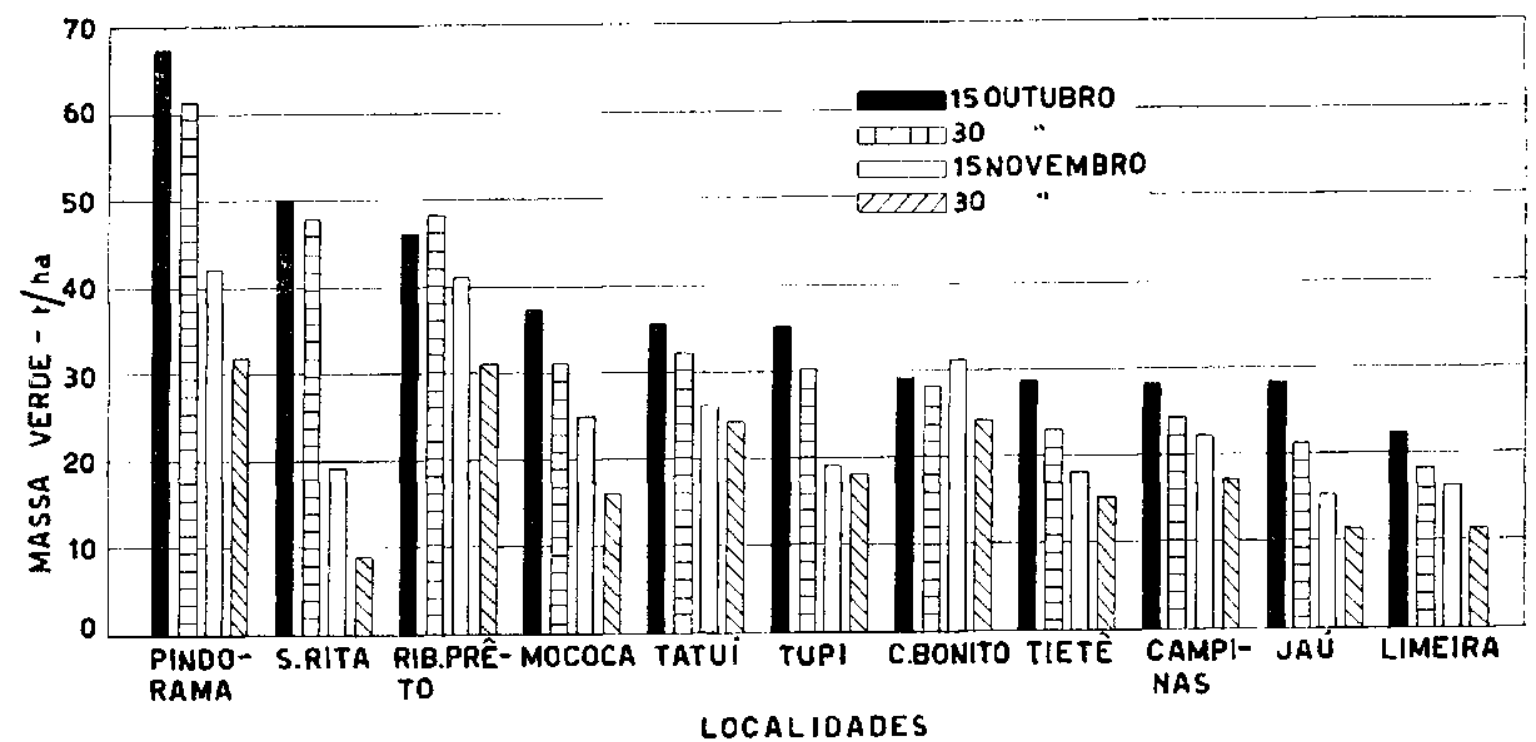

Figrna 1.-Producós médias de caules verdes enfollados de $I$. lobata em tonelarlas

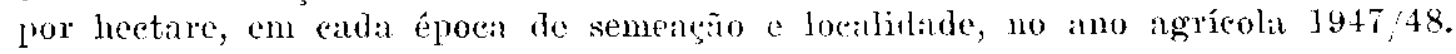

\section{$3.2-$ ANO .IGRICOLA $1948 / 49$}

Neste ano agrícola, foram instalados, novamente, nas mesmas localidades, em prosseguimento da pesquisa iniciada no ano agrícola anterior, os experimentos para determinar o efeito da época de semeação sôbre a produção de guaxima, em caules verdes enfolhados. A distância entre linhas foi modificada de 20 para 30 centímetros, conservando-se, porém, na linha, a mesma densidade de semeação, isto é, 1 grama de sementes por metro linear.

Qtando 2.-Produçãc média de caules verdes enfolhados da $C$. lobata, em quilos por subparchos de $10 \mathrm{~m}^{2}$ em eada época de semeação e localidade, nos experim?ntos: d. ano agrícola $1948 / 49$. Médias de 4 repetições

\begin{tabular}{|c|c|c|c|c|c|c|}
\hline \multirow[t]{2}{*}{ Localidades } & \multicolumn{4}{|c|}{$\begin{array}{c}\text { Produção média de mitsa verde nas } \\
\text { époets }\end{array}$} & \multirow{2}{*}{$\begin{array}{c}\text { "li" } \\
\text { relativo } \\
\text { a } \\
\text { épocas( } 1)\end{array}$} & \multirow{2}{*}{$\begin{array}{c}\text { Diferença } \\
\text { mivima } \\
\text { signifieativa } \\
(\mathrm{P}=0.05)\end{array}$} \\
\hline & Primeirt & Segund:1 & Terceira & Quarta & & \\
\hline & $\operatorname{lgg}$ & $k g$ & $k g$ & $\mathrm{~kg}$ & & $k g$ \\
\hline Pindorama _.. & 60,5 & 56,6 & 43,6 & 10,1 & $18,97 * *$ & \pm 3.6 \\
\hline Mococa ......... & 33,1 & 32,4 & 26,1 & 20,2 & $9,73 * *$ & $\pm 3,1$ \\
\hline Ribeirão Prêto. & 47,5 & 46,0 & 49,2 & 34,7 & $9,63^{* *}$ & $\pm 3,1$ \\
\hline Capão Bonito..... & 34,5 & 31,2 & 28,0 & 23,4 & $4,96^{*}$ & $\pm 3,4$ \\
\hline Tatuí _............ & 55,7 & 44,0 & 61,3 & 39.9 & $1,53 \mathrm{~ns}$. & ........... \\
\hline I.incira . & 12,6 & 12,7 & 8,6 & 7,1 & 2,27 is.s. & - \\
\hline Santa Rita & 40,7 & 37,5 & 22,0 & 17.7 & $26,85^{* *}$ & $\pm 4,7$ \\
\hline Jaú & 28,1 & 28,7 & 23,5 & 21,3 & $7.05 * *$ & $\pm 2,1$ \\
\hline Campinas & 31,4 & 29,0 & 27,1 & 18,3 & $6,39^{*}$ & $\pm 3,6$ \\
\hline Tietê. & 43,4 & 38,2 & 37,1 & 24.0 & $11,54 * *$ & $\pm 4,0$ \\
\hline Tupi & 36,1 & 33,0 & 29,7 & 31,0 & 2,16 n.s. & $\ldots \ldots$ \\
\hline
\end{tabular}


No quadro 2 se indicam as produções médias de caules verdes enfolhados, em quilos, para cada época de semeação e localidade, assim como o efeito das diferentes épocas de semeação sôbre a produção e os valores da diferença mínima significativa para $\mathrm{P}=0,05$.

Os dados do quadro 2 mostram que em seis localidades - Pindorama, Mococa, Ribeirão Prêto, Santa Rita, Jaú e Tietê - o efeito das épocas de semeação sôbre a produção de caules verdes enfolhados foi altamente significativo, ao passo que em duas localidades - Capão Bonito e Campinas - o efeito já foi apenas significativo. Entretanto, em duas localidades - Tatuí e Tupi - ao contrário do ano agrícola anterior, o efeito das épocas de semeação não foi significativo.

De modo geral, as produções obtidas neste ano agrícola foram superiores àquelas do ano agrícola anterior, confirmando-se, novamente, a superioridade das duas primeiras épocas de semeação, correspondendo a 15 e 30 de outubro, sôbre as duas épocas mais tardias, correspondendo a 15 e 30 de novembro.

$\mathrm{Na}$ figura 2 estão representadas, gràficamente, as produções médias de caules verdes enfolhados, em toneladas por hectare, em cada época de semeação e localidade experimentada.

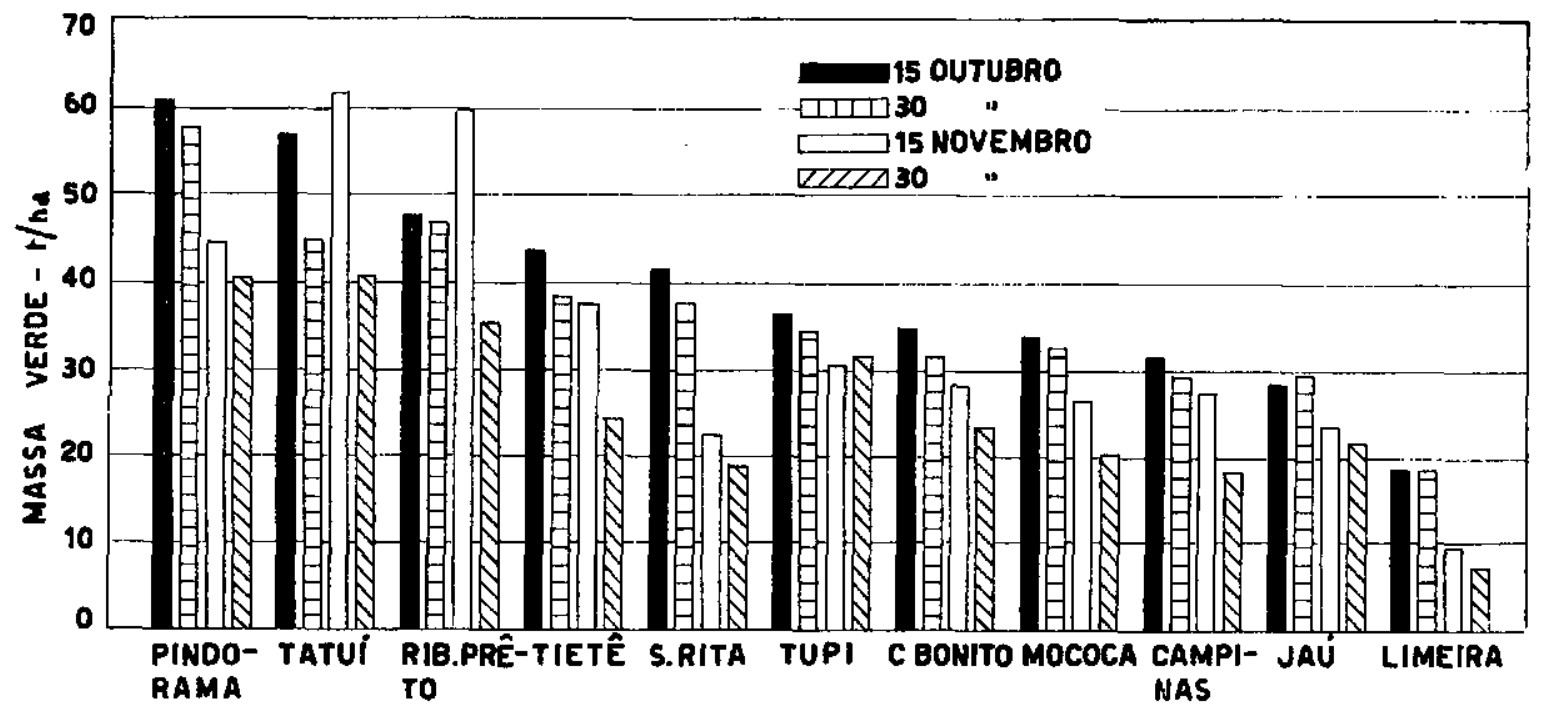

LOCALIDAOES

Figura 2.-Produções médias de caules verdes enfollıados de $U$. lobata em toneladas por hectare, em eada época de seneação e localidade, no ano agrícola 1948/49.

\section{3 - ANO AGRÍCOLA $1949 / 50$}

Finalizando a pesquisa aqui relatada, foram instalados, no ano agrícola 1949/50, mais dez experimentos nas mesmas localidades dos dois anos agricolas anteriores, tendo-se deixado de instalar, entretanto, por falta de sementes, o correspondente a Campinas.

Durante a execução dos experimentos dêste ano agrícola, não houve ocorrência a relatar. 
No quadro 3 constam as produções médias de caules verdes enfolhados, em quilos, para cada época de semeação e localidade, assim como o efeito das épocas de semeação sôbre a produção e os valores da diferença mínima significativa para $\mathbf{P}=0,05$.

Quadro 3.-Produção média de caules verdes enfolhados, em quilos, por subparcela de $10 \mathrm{~m}^{2}$, em cada época de semeação e localidade, nos experimentos do ano agrícola 1949/50. Médias de 4 repetiçoes

\begin{tabular}{|c|c|c|c|c|c|c|}
\hline \multirow{2}{*}{ Localidades } & \multicolumn{4}{|c|}{$\begin{array}{c}\text { Produção média de massa verde nas } \\
\text { épocas }\end{array}$} & \multirow{2}{*}{$\begin{array}{c}\text { "F"' } \\
\text { relativo } \\
a \\
\text { epocas(1) }\end{array}$} & \multirow{2}{*}{$\begin{array}{c}\text { Diferença } \\
\text { mínima } \\
\text { significativa } \\
(\mathrm{P}=0,05)\end{array}$} \\
\hline & Primeira & Segunda & Terceira & Quarta & & \\
\hline & $\operatorname{lgg}$ & $\operatorname{lkg}$ & $k g$ & $k g$ & & $k g$ \\
\hline Pindorama ......... & 58,0 & 50,4 & 45,4 & 27,9 & $37,95^{* *}$ & $\pm 3,3$ \\
\hline Mococa & 41,5 & 35,7 & 35,1 & 24,2 & $10,30^{* *}$ & $\pm 3,6$ \\
\hline Ribeirão Prêto .... & 59,0 & 46,5 & 39.7 & 29,5 & $6,62^{*}$ & $\pm 7,7$ \\
\hline Capão Bonito & 36,5 & 36,9 & 30,4 & 29,1 & 1,46 n.s. & $\cdots$ \\
\hline Tatuí ................. & 94,5 & 104,5 & 64,7 & 72,2 & 1,90 n.s. & \\
\hline Limeira & 17,4 & 18,0 & 17,0 & 13,1 & 1,13n.s. & \\
\hline Santa Rita..... & 44,2 & 30,5 & 29,7 & 20,5 & $299,35^{* *}$ & $\pm 1,0$ \\
\hline Jaú. & 48,8 & 45,2 & 35,8 & 38,8 & 3,64n.s. & \\
\hline Tietê. & 37,0 & 33,0 & 15,2 & 14,2 & $18,45^{* *}$ & $\pm 4,4$ \\
\hline Tupi & 59,4 & 42,8 & 41,4 & 28,5 & $8,54^{* *}$ & $\pm 6,9$ \\
\hline
\end{tabular}

(I) $^{*}=$ significativo $(5 \%)^{* *}=$ altamente significativo n.s. $=$ não significativo.

Os dados do quadro 3 mostram que no ano agrícola 1949/50, em cinco localidades - Pindorama, Mococa, Santa Rita, Tietê e Tupi - o efeito das épocas de semeação sôbre a produção de caules verdes enfolhados da $U$. lobata foi altamente significativo, ao passo que em quatro localidades Capão Bonito, Tatuí, Limeira e Jaú - as épocas de semeação não influíram significativamente sôbre a produção. Em Ribeirão Prêto, a influência da época foi apenas significativa.

As produções obtidas neste ano agrícola nas localidades de Ribeirão Prêto, Jaú e Tupi foram superiores àquelas dos anos agrícolas anteriores, sendo que em Tatuí, além de terem sido bastante superiores, nas diversas épocas, podem ser consideradas como extraordinárias.

$\mathrm{Na}$ figura 3 estão representadas as produções médias de caules verdes enfolhados, em toneladas por hectare, em cada época de semeação e localidade experimentada. 


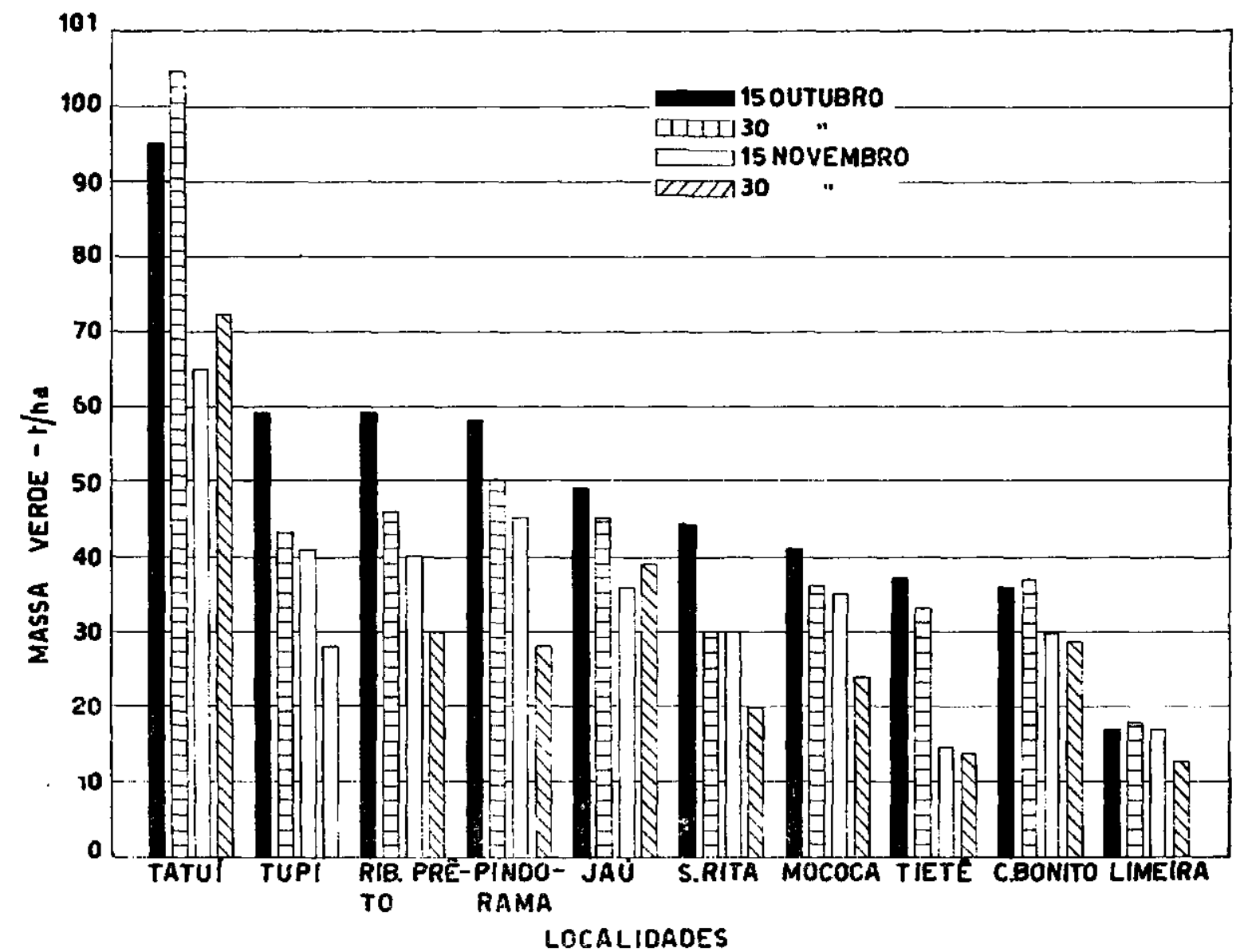

Figura 3.-Prodapōes médias de entiles verdes enfollados le $T$. lobata em toneladas por hectare, em cada épocal de semutaģăo e localirlade, no ano agrícola 1949/50.

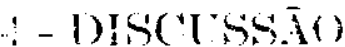

Conciderando a produę̃o de caules verdes enfolhados da última época do semenc(âa -... 30 de novembro -.... igual a 100, que em apenas três exceções não corresponden às producơes mais baixus, obteríamos para as demais épocar: em cada localidade cano agrícola, as proporçoes apresentadas no quadro 4.

Os dados dêsse quadro most ram que, em média, nos três anos agrícolas considerados, a produção de caules verdes cnfolhados, correspondente à primeira, segunda e terceira épocas de semeação, em relação àquela da última época (quarta época), foi superior em $74 \%, 54 \%$ e $27 \%$, respectivamente.

No quadro 5 estão indicados os dados sôbre o número de dias decorridos na germinação das sementes e no início de florescimento das plantas das três últimas épocas de semeação, em relação aos da primeira época, para os três anos agrícolas de experimentação. 
Qunomo 4.-.- Produçües médias de eutules verdes enfolhados da $U$. labala das primeiras épocas de scmeação, em relação às da última época, consideradas igual a 100 , por localiclade e ano agrícola

\begin{tabular}{|c|c|c|c|c|c|c|c|c|c|}
\hline \multirow{2}{*}{ I socalidades } & \multicolumn{3}{|c|}{$1947: 48$} & \multicolumn{3}{|c|}{$1948 / 49$} & \multicolumn{3}{|c|}{$1949 / 50$} \\
\hline & $\begin{array}{l}\text { Pri- } \\
\text { meira }\end{array}$ & $\begin{array}{l}\text { Se- } \\
\text { gunda }\end{array}$ & $\begin{array}{l}\text { Ter- } \\
\text { ceira }\end{array}$ & $\begin{array}{l}\text { Pri- } \\
\text { morira }\end{array}$ & $\begin{array}{c}\text { Se- } \\
\text { gunda }\end{array}$ & $\begin{array}{l}\text { Ter- } \\
\text { ceira }\end{array}$ & $\begin{array}{l}\text { Pri- } \\
\text { meira }\end{array}$ & $\begin{array}{l}\text { Se- } \\
\text { gundat }\end{array}$ & $\begin{array}{l}\text { Ter- } \\
\text { ceira }\end{array}$ \\
\hline Pindorama.- & $20 i$ & 189 & 129 & 151 & 141 & 109 & 208 & 181 & 163 \\
\hline Mococa............... & 229 & 190 & 153 & 164 & 160 & 129 & 171 & 147 & 145 \\
\hline IRibeirão Prêto & 147 & 153 & 123 & 137 & 132 & 142 & 200 & 158 & 134 \\
\hline Capão Bonito & 124 & 119 & 130 & 147 & 133 & 120 & 125 & 127 & 104 \\
\hline 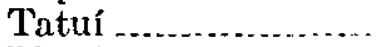 & 146 & 133 & 107 & 139 & 110 & 154 & 131 & 145 & 90 \\
\hline Limeira .................... & 204 & 1.66 & 144 & 177 & 179 & 121 & 133 & 137 & 130 \\
\hline 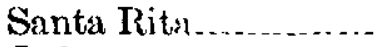 & $529 *$ & $409^{*}$ & $206^{*}$ & $230 *$ & 212 & 124 & 216 & 149 & 145 \\
\hline Jaú & 245 & 184 & 131 & 132 & 135 & 110 & 126 & 116 & 92 \\
\hline Campinas ................ & 161 & 135 & 128 & 171 & 158 & 148 & & & \\
\hline Tietế & 185 & 149 & 116 & 181 & 159 & 154 & 260 & 232 & 107 \\
\hline Tupi & 196 & 170 & 106 & 116 & 106 & 96 & 208 & 150 & 145 \\
\hline Média geral... & 184 & 159 & 127 & 159 & 148 & 128 & 178 & 154 & 125 \\
\hline
\end{tabular}

* não computados na nédia geral.

Os dados do quadro 5 mostram que, embora as semeações tivessem sido feitas a intervalos quinzenais, e a semeação da última época tivesse sido feita 45 dias depois da primeira, o início de florescimento das plantas da última época de semeação foi, em média, apenas de cêrca de 10, 8 e 7 dias mais tarde, nos anos agrícolas de 1947/48, 1948/49 e 1949/50, respectivamente.

Quadro 5.-Média de dias decorridos na germinação das sementes e início de florescimento da $U$. lobata da segunda, terceira e quarta épocas de semeação, em relação à primeira época

\begin{tabular}{|c|c|c|c|c|c|c|}
\hline \multirow[t]{2}{*}{ Ano agrícola } & \multicolumn{3}{|c|}{$\begin{array}{c}\text { Intervalo em dias na germi- } \\
\text { nas"̃o em relaço à primeira } \\
\text { ćpoca }\end{array}$} & \multicolumn{3}{|c|}{$\begin{array}{c}\text { Intervalo cm dias no início } \\
\text { do florescimento em relação } \\
\text { i primeira epoca }\end{array}$} \\
\hline & Segunda & Terceira & Quarta & Segundit & Terceira & Quarta \\
\hline $1947 / 48 *$ & 14,1 & 29,5 & 44,2 & 3,0 & 8,8 & 10,0 \\
\hline $1948 / 49 *$ & 8,9 & 22,9 & 43,9 & 2,0 & 5,9 & 7,6 \\
\hline $1949 / 50 * \ldots$ & 12,7 & 27.4 & 41,4 & 2,3 & 5,7 & 7,2 \\
\hline
\end{tabular}


No quadro 6 estão indicados os dados referentes à altura média das plantas, em centímetros, por ocasião da colheita, e ao número médio de dias decorridos entre a germinação das sementes e início de florescimento das plantas de guaxima, nas diferentes épocas de semeação, durante os anos agrícolas ali considerados. Os resultados dêsse quadro mostram que essa planta exibe uma evidente reação à duração do dia (fotoperiodismo), e que, quanto mais tardia a época de semeação, tanto menor a altura média das plantas e a duração do ciclo vegetativo. Em consequência, a produção de caules verdes enfolhados foi decrescendo da primeira à última época de semeação experimentada.

Qvanro 6.--Altura média das plantas de $U$. lobata, em centímetros, por ocasiāo do corte, e número médio de dias decorridos entre a germinação e início de florescimento, nas diferentes épocas de semeação, durinte os anos agrícolas de 1947/48, $1948 / 49$ e $1949 / 50(1)$

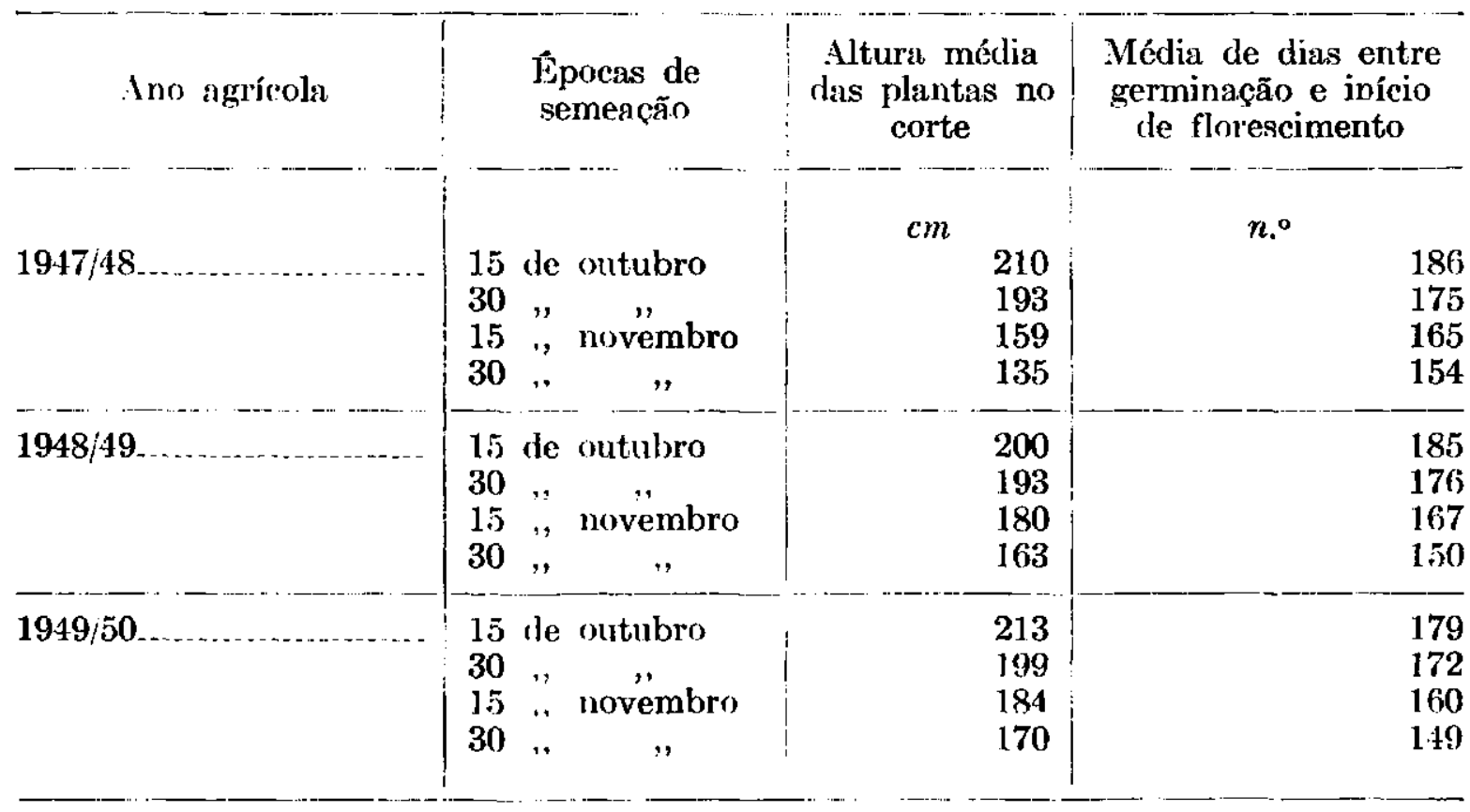

(1) Módias de 9 lccalidades.

O exame dos registos de chuvas, nas localidades estudadas, mostrou que não houve nenhuma relação entre as produções das diferentes épocas de semeação e as precipitações pluviométricas ocorridas durante o ciclo vegetativo das plantas.

Analisando-se, conjuntamente, para cada localidade, as produções obtidas no triênio agrícola 1947/50, obtêm-se os "F" calculados para os efeitos ano, época e a intcração ano x época, indicados no quadro 7 .

Os dados do quadro 7 mostram que o efeito ano foi, exceto para as localidades de Ribeirão Prêto e Santa Rita, altamente significativo, isto é, ocorreu no triênio de experimentação grande variação na produção devida a anos, o mesmo acontecendo em relação ao efeito épocas de semeação, exceto para a localidade de Tatuí. Em uma única localidade, Santa Rita, $a$ interação ano $x$ época foi altamente significativa, isto é, houve um com- 
QUadro 7.-Resultados do "F" calculado para os efeitos anos e épocas de semeação, assim como para a interação ano $x$ época, da análise das produções do triênio agrícola $1947 / 50$, por localidade

\begin{tabular}{|c|c|c|c|}
\hline & & calculado ( & \\
\hline Iocalidades & Ano & Epoca & $\begin{array}{c}\text { Interação } \\
\text { ano x época }\end{array}$ \\
\hline Pindorama ...... & $4,54^{*}$ & $65,33^{* *}$ & $2,62 *$ \\
\hline Mococa & $13,65 * *$ & $37,36 * *$ & 1,08 \\
\hline Ribeirão Prêto & 0,64 & $18,04 * *$ & 1,57 \\
\hline Capão Bonito & $5,07 *$ & $6,49^{*}$ & 0,92 \\
\hline 'Tatú́ & $36,39^{* *}$ & 2,21 & 1,74 \\
\hline Limeira. & $15,92 * *$ & $8,93 * *$ & 1,00 \\
\hline Santa Rita & 2,22 & $229,84 * *$ & $15,19 * *$ \\
\hline Jaú. & $136,07 * *$ & $20,47 * *$ & 1,59 \\
\hline Tiet $\hat{e}$ & $32,95^{* *}$ & $29,25 * *$ & $2,88^{*}$ \\
\hline 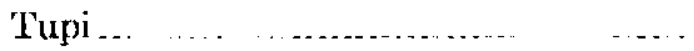 & $33,85 * *$ & $18,63^{* *}$ & $3,44^{*}$ \\
\hline
\end{tabular}

(1) $)^{* *}=$ allamente significativo ${ }^{*}=$ significalivo (5\%).

portamento difercncial das épocas nos diferentes anos agrícolas, ao passo que em três localidades-Pindorama, Tietê a Tupi--o comportamentu diferencial das épocas de semeação foi menos acentuado, isto é, apenas

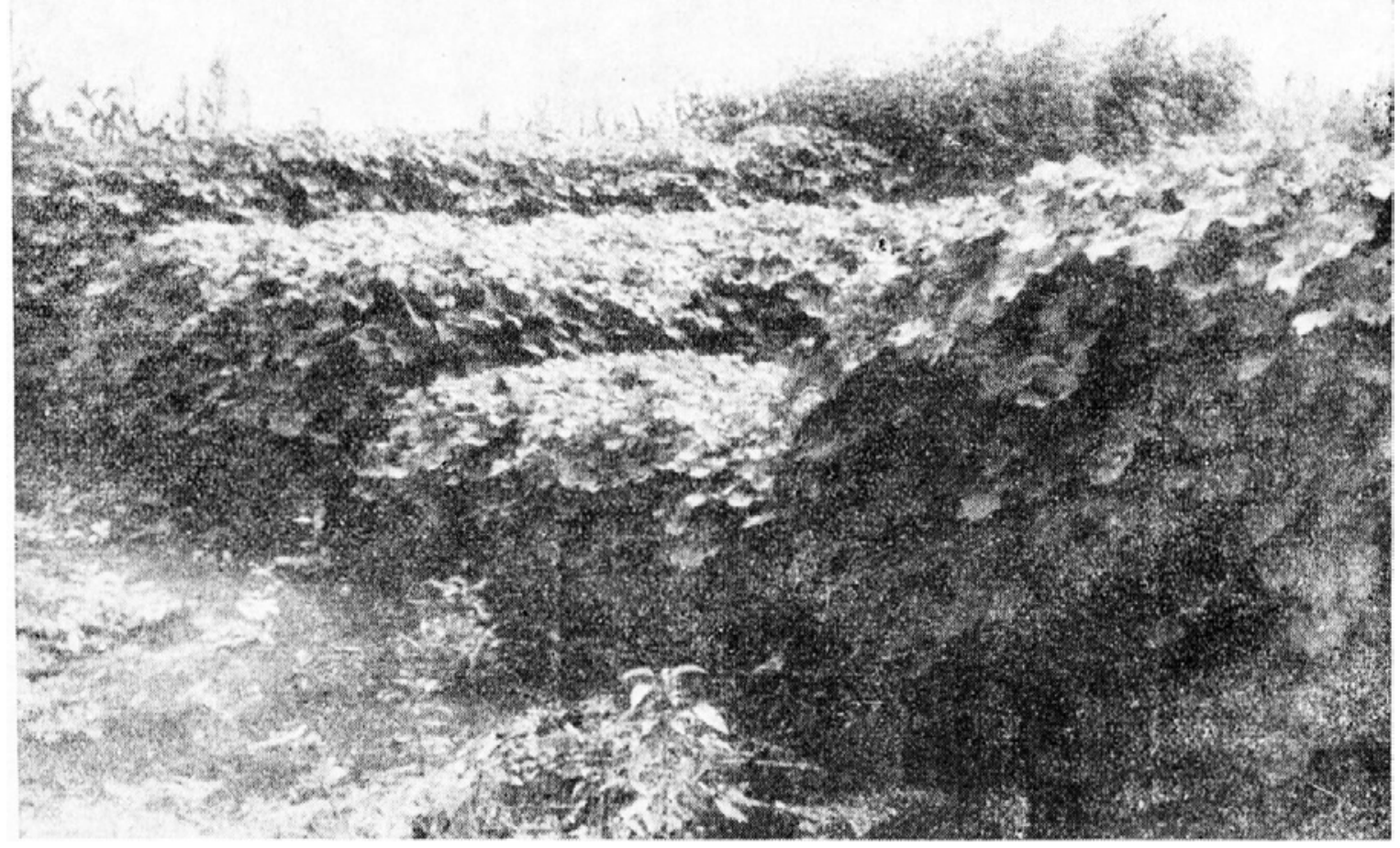

Figtra 4.-Vista da experiência de époea de semeação em Ribeirão Prêto, tirada em fevereiro de 1948, mostrando, da esquerta para a direita, as subparcelas correspondentes às seguintes épocas: 15 de outubro, 15 de novembro, 30 de novembro e 30 de outubro. 
significativo a 5\%. Nas demais localidades - Mococa, Ribeirão Prêto, Capão Bonito, Tatuí, Limeira e Jaú - as épocas de semeação mantiveram-se estáveis nos anos agrícolas considerados.

Finalmente, supondo apenas as produçסes de caules verdes enfolhados, obtidas na primeira época de semeação, que foi, em geral, a melhor época, e a percentagem de fibra de $5,2 \%$, determinada para a $U$. lobata, em 1944 , obteríamos, em média, no triênio agrícola 1947/50, por localidade, as produções prováveis de caules verdes enfolhados e fibra, em quilos por hectare, indicadas no quadro 8.

QUADRo 8.-Produção média de caules verdes enfolhados e "fibra provável", em quilos por hectare para o triênio agrícola 1947/50 e por localidade, na primeira época de semeação (15 de outubro)

\begin{tabular}{|c|c|c|}
\hline Localidades & $\begin{array}{l}\text { Caules verdes } \\
\text { enfolhados }\end{array}$ & Fibra provável \\
\hline & $k g / h a$ & $k g / h a$ \\
\hline Pindorama ...... & 61700 & 3208 \\
\hline Mococa & 37200 & 1934 \\
\hline Ribeirão Prêto..... & 50900 & 2647 \\
\hline Capão Bonito .... & 33400 & 1737 \\
\hline Tatuí & $6 \mathrm{~L} 900$ & 3219 \\
\hline Limeira & 17400 & 905 \\
\hline - & 44800 & 2330 \\
\hline - & 34900 & 1815 \\
\hline c. & 36300 & 1888 \\
\hline - & 43400 & 2257 \\
\hline Campinas $(1)$ & 29800 & 1550 \\
\hline
\end{tabular}

(1) Apenas o biênio agricola 1947/49.

Convém esclarecer, entretanto, que os dados indicados no quadro 8 não devem ser interpretados como produções a serem esperadas nas grandes culturas, mas apenas como indicativos de "produção provável", apesar de não terem sido aqui considerados outros fatôres que podem intervir na produção, como densidade de semeação, adubação, etc.

\section{SUMMARY}

In order to determine the effect of planting time on growth and yield of caesar weed (Urena lobata $\mathrm{L}$.), experimental trials in randomized blocks were conducted in 11 localities of the State of São Paulo, during the crop years 1947/48, 1948/49 and 1949/50.

Plantings were made at 15 day intervals, beginning October 15, and ending November 30, in rows $20 \mathrm{~cm}$ appart and seeded at the rate of 50 kilograms of seed per hectare in the 1947/48 plartings, and in rows $30 \mathrm{~cm}$ appart and seeded at the rate of 33 kilograms of seed per hectare in the 1948/49 and 1949/50 plantings.

Harvest operations were carried out at the time when the plants were in full bloom state and green weight of foliated stems were determined. 
The following conclusions can be drawn:

1 - Higher yields of green foliated stems were obtained from plantings made on October 15 and October 30.

2 - Average height of the plants decreased from the first (Oct. 15) to the last (Nov. 30) plantings.

3 - There was a difference of about 8 days in the time of opening of the first flower between the plants of the first and last plantings.

The results obtained in this investigation showed that caesar weed is a fibrous bast plant well adapted to cultivation on various soil types and localities of the State of São Paulo. 